\title{
ANTIBACTERIAL RESISTANCE PATTERN OF PSEUDOMONAS AERUGINOSA ISOLATED FROM CLINICAL SAMPLES AT A GENERAL HOSPITAL IN PADANG, WEST SUMATRA, INDONESIA
}

\author{
RUSTINI RUSTINI ${ }^{1 *}$, JAMSARI JAMSARI ${ }^{2}$, MARLINA MARLINA ${ }^{1}$, NASRUL ZUBIR ${ }^{3}$, YORI YULIANDRA ${ }^{1}$
}

${ }^{1}$ Department of Pharmacy, Faculty of Pharmacy, Andalas University, Kota Padang, Sumatera Barat, Indonesia. ${ }^{2}$ Department of Genomic and Molecular Breeding, Andalas University, Kota Padang, Sumatera Barat, Indonesia. ${ }^{3}$ Department of Internal Medicine, Dr. M. Djamil Hospital Padang, Kota Padang, Sumatera Barat, Indonesia. Email: rustini@ffarmasi.unand.ac.id

Received: 17 March 2017, Revised and Accepted: 27 April 2017

ABSTRACT

Objectives: Pseudomonas aeruginosa is an opportunistic pathogen that has an innate resistance to some antibiotics. This bacterium is one of the most common causes of nosocomial infections that include surgical wound infections, burns, and urinary tract infections. The bacteria have been reportedly resistant to many antibiotics and have developed multidrug resistance (MDR). The objective of the study was to determine the resistance pattern of P. aeruginosa isolated from clinical samples of patients against some major antibiotics.

Methods: Isolates of $P$. aeruginosa were obtained from clinical sample of urine, sputum, swabs, pus, feces, and blood and cultured in cetrimide agar. $P$. aeruginosa ATCC 27853 was used as a positive control. The antibacterial susceptibility testing was conducted against 13 antibiotics: Ceftazidime, cefotaxime, ceftriaxone, cefoperazone, ciprofloxacin, levofloxacin, ofloxacin, gentamicin, amikacin, piperacillin, ticarcillin, meropenem, and imipenem. The examination was carried out using agar diffusion method of Kirby-Bauer and following the standards from Clinical and Laboratory Standards Institute (CLSI).

Results: The results showed that bacterial resistance was established against all tested antibiotics. The highest number of resistance was shown against ceftriaxone (44.21\%), whereas the most susceptibility was exhibited against amikacin (only 9.47\% of resistance). MDR P. aeruginosa (MDRPA) was detected on almost all clinical samples tested, except the feces. The sample with the highest percentage of MDRPA was the pus.

Conclusion: The study concludes that the most effective antibiotic against $P$. aeruginosa is amikacin (91.51\%), whereas the most resistance is exhibited to ceftriaxone (43.16\%).

Keywords: Pseudomonas aeruginosa, Antibiotic resistance, Multidrug resistance, Clinical samples, Antibacterial susceptibility testing.

(C) 2017 The Authors. Published by Innovare Academic Sciences Pvt Ltd. This is an open access article under the CC BY license (http://creativecommons. org/licenses/by/4. 0/) DOI: http://dx.doi.org/10.22159/ajpcr.2017.v10i8.18539

\section{INTRODUCTION}

Pseudomonas aeruginosa is an opportunistic pathogenic bacterium that is well known as an important cause of nosocomial infections [1]. The incidence of nosocomial infections in the world which are caused by P. aeruginosa is approximately $10-15 \%$ and $10-20 \%$ in the Intensive Care Unit, usually occurs in patients with septicemia, cystic fibrosis, burns, and wound infection [2-4]. Successful treatment of infectious diseases is determined by rational use of antibiotics, especially the efficacy of the drugs. Recently, this bacterium is reported to have developed resistance and even multidrug resistance (MDR) against antibiotics [5-7]. Some mechanisms of bacterial resistance have been recognized and well understood. Bacteria may develop the resistance through the production of beta-lactamase enzyme that can destroy the antibiotic, changing intracellular targets of antibiotics, and efflux pump [8].

MDR P. aeruginosa (MDRPA) is a condition, in which the bacteria are resistant to three or more antibiotics [9]. The incidence of MDRPA was reported to range from $0.6 \%$ to $32 \%$. Its prevalence increased over the last decade in hospitalized patients, resulting in fewer choices for successful treatment [10]. In a General Hospital in Padang city, Indonesia, Pseudomonas sp. has been classified into the MDR bacteria with a considerable percentage within 3 years: $88 \%$ in $2010,61 \%$ in 2011 , and $66 \%$ in 2012 [11].

The objective of this research was to study the pattern of $P$. aeruginosa bacterial resistance isolated from urine, sputum, swabs, pus, feces, and blood of hospitalized patients and to determine the percentage of $P$. aeruginosa that exhibits MDR against some popular antibiotics.

\section{MATERIALS AND METHODS}

\section{Drugs and bacterial media}

Antimicrobial susceptibility discs and bacterial growth media were purchased from Oxoid (Thermo Scientific Microbiology Pvt. Ltd.). Control sample $P$. aeruginosa ATCC 27853 was obtained from the National Agency of Drug and Food Control, Republic of Indonesia in Padang city, West Sumatra.

\section{Samples collection and preparation}

Isolate samples of $P$. aeruginosa were obtained from urine, sputum, swabs, pus, feces, and blood of psatsients from a General Hospital in Padang, West Sumatra, Indonesia. All samples were cultured in medium cetrimide agar. Greenish or yellow-green fluorescence after incubation for $24 \mathrm{hrs}$ indicated a positive isolate of the bacterium. All procedures and experimental protocols were approved by the Ethical Committee of Faculty of Medicine, Andalas University, No: 062/KEP/FK/2015.

\section{Antimicrobial susceptibility testing}

The antimicrobial activity of antibiotics was determined using MuellerHinton agar medium. Antimicrobial susceptibility testing of all cultures was conducted against 13 different antibiotics: Ceftazidime $(30 \mu \mathrm{g})$, cefotaxime $(30 \mu \mathrm{g})$, ceftriaxone $(30 \mu \mathrm{g})$, cefoperazone $(30 \mu \mathrm{g})$, ciprofloxacin $(5 \mu \mathrm{g})$, levofloxacin $(5 \mu \mathrm{g})$, ofloxacin $(5 \mu \mathrm{g})$, gentamicin $(10 \mu \mathrm{g})$, amikacin $(30 \mu \mathrm{g})$, piperacillin $(100 \mu \mathrm{g})$, ticarcillin $(75 \mu \mathrm{g})$, meropenem $(10 \mu \mathrm{g})$, and imipenem $(10 \mu \mathrm{g})$. P. aeruginosa ATCC 27853 was used as a positive control.

Blocked diameter produced by the antibiotics was compared to the standard according to antimicrobial susceptibility testing standard of the Clinical and Laboratory Standards Institute (CLSI) [12]. Further 
test was conducted to explore the susceptibility of the sample cultures against each antibiotics. The number of sample cultures was then counted based on their susceptibility and classified to sensitive (S), intermediates (I), and resistant (R). P. aeruginosa was considered to exhibit MDR when the bacterial resistance was developed against three or more antibiotics used in the test.

\section{RESULTS}

A total of 95 isolates of $P$. aeruginosa were used in the study. All samples were isolated from sputum (35), swab (22), pus (23), urine (10), blood (3), and stool (2) of patients. Table 1 shows the diameter of clear zone produced by antibiotics when tested to the control culture P. aeruginosa ATCC 27853 compared to standard according to CLSI. The susceptibility of entire sample cultures against each antibiotic is shown in Table 2 and Fig. 1. Meanwhile, the result of susceptibility testing per clinical samples is presented in Fig. 2

The result of bacterial susceptibility testing showed that approximately $36 \%$ of the sample isolates were MDRPA, in which the bacteria were resistant to at least three antibiotics. Meanwhile, $18 \%$ of the sample cultures were also resistant to one to two antibiotics. On the other hand, the sensitive bacterial culture to antibiotics was below a half of the samples (46\%).

\section{DISCUSSION}

The antibacterial susceptibility testing in the present study was carried out by the agar diffusion method. The diameter measured in this method is inhibition of bacterial growth, which appears as a clear zone around

Table 1: Antibacterial activity of antibiotics against control Pseudomonas aeruginosa ATCC27853

\begin{tabular}{llll}
\hline \multirow{2}{*}{ No. } & Antibiotic & \multicolumn{2}{c}{ Diameter of inhibition zone (mm) } \\
\cline { 3 - 4 } & & Sample culture & CLSI standard \\
\hline 1 & Ceftazidime & 22.00 & $22-29$ \\
2 & Cefotaxime & 20.25 & $18-22$ \\
3 & Ceftriaxone & 26.00 & $17-23$ \\
4 & Cefoperazone & 26.00 & $23-29$ \\
5 & Ciprofloxacin & 38.50 & $25-33$ \\
6 & Levofloxacin & 36.00 & $19-26$ \\
7 & Ofloxacin & 32.25 & $17-21$ \\
8 & Gentamicin & 20.00 & $16-21$ \\
9 & Amikacin & 24.00 & $18-26$ \\
10 & Piperacillin & 29.50 & $25-33$ \\
11 & Ticarcillin & 26.50 & $21-27$ \\
12 & Meropenem & 40.25 & $27-33$ \\
13 & Imipenem & 33.68 & $20-28$ \\
\hline
\end{tabular}

CLSI: Clinical and Laboratory Standards Institute

Table 2: Percentage of bacterial susceptibility category of Pseudomonas aeruginosa against 13 different antibiotics

\begin{tabular}{lllll}
\hline \multirow{2}{*}{ No. Antibiotic } & \multicolumn{3}{l}{ Bacterial susceptibility (\%) } \\
\cline { 3 - 5 } & & Susceptible & Intermediate & Resistant \\
\hline 1 & Ceftazidime (CAZ) & $65(68.42)$ & $5(5.26)$ & $25(26.32)$ \\
2 & Cefotaxime (CTX) & $20(21.05)$ & $36(37.89)$ & $39(41,05)$ \\
3 & Ceftriaxone (CRO) & $47(49.47)$ & $6(6.32)$ & $42(44.21)$ \\
4 & Cefoperazone (CFP) & $53(55.79)$ & $6(6.32)$ & $36(37.89)$ \\
5 & Ciprofloxacin (CIP) & $67(70.53)$ & $3(3.16)$ & $25(26.32)$ \\
6 & Levofloxacin (LEV) & $66(69.47)$ & $9(9.47)$ & $20(21.05)$ \\
7 & Ofloxacin (OFX) & $62(65.26)$ & $2(2.11)$ & $31(32.63)$ \\
8 & Gentamicin (CN) & $61(64.21)$ & $5(5.26)$ & $29(30.53)$ \\
9 & Amikacin (AK) & $85(89.47)$ & $1(1.05)$ & $9(9.47)$ \\
10 & Piperacillin (PRL) & $77(81.05)$ & 0 & $18(18.95)$ \\
11 & Ticarcillin (TIC) & $69(72.63)$ & 0 & $26(27.37)$ \\
12 & Meropenem (MEM) & $71(74.74)$ & $1(1.05)$ & $23(24.21)$ \\
13 & Imipenem (IPM) & $71(74.74)$ & $1(1.05)$ & $23(24.21)$ \\
\hline
\end{tabular}

the disc. This diameter represents the potency of antibacterial activity of the drug [13]. This technique is an important method in assessing the microbial susceptibility testing that has been used worldwide for more than 50 years. The result of such technique is considered to show comparable result to other methods, such as microdilution technique $[14,15]$.

In the present study, the highest level of resistance of $P$. aeruginosa was shown against ceftriaxone that reached $44 \%$ out of 95 bacterial culture samples. Some reports also state that this antibiotic has been facing an extensive microbial resistance across the globe. The resistance rate for this drug in the present study is greater than the result of a study in 2012 conducted at three hospitals in South West Nigeria, in which $34.5 \%$ were resistant to ceftriaxone [16]. Several studies have confirmed that Pseudomonas aeruginosa is mostly resistant against ceftriaxone $[3,17,18]$. However, this high level of resistance is not quite surprising as some suggest that ceftriaxone has considerably low activity against $P$. aeruginosa $[19,20]$

High rate of resistance to cephalosporin class (e.g., ceftriaxone) occurs because of a mutation that results in the production of PenicillinBinding Proteins (PBP). In addition, the resistance may also occur because of mutations that altered porin, beta-barrel proteins that cross a cellular membrane and act as a pore, that is, involved in the transport across the membrane. This alteration causes cephalosporins cannot reach the cytoplasmic membrane where the PBP is located. The ability of this bacterium to produce lactamase may also increase the resistance to antibiotics. This enzyme is known to hydrolyze the lactam ring bond resulted in the inactivation of antibiotics [21].

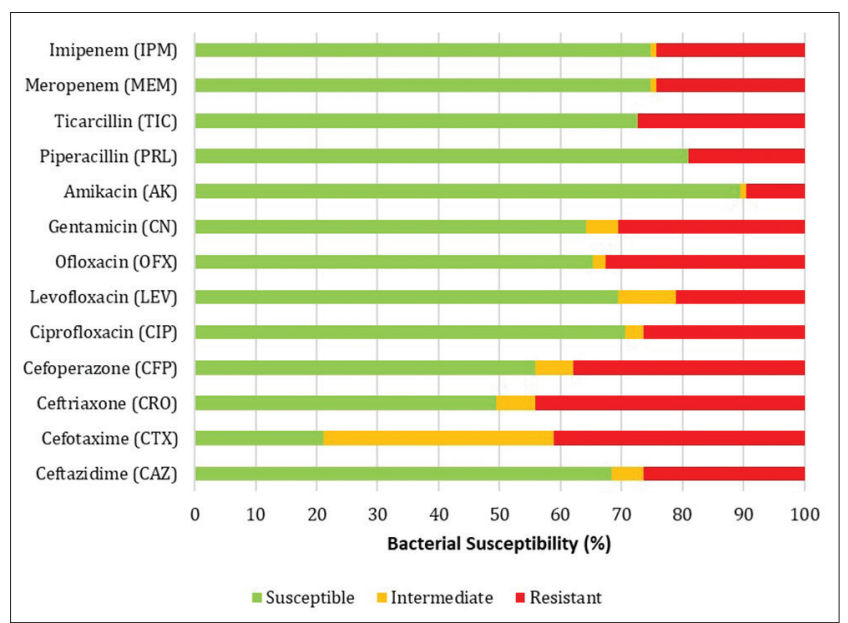

Fig. 1: Bacterial susceptibility of clinical samples against 13 different antibiotics $(n=95)$

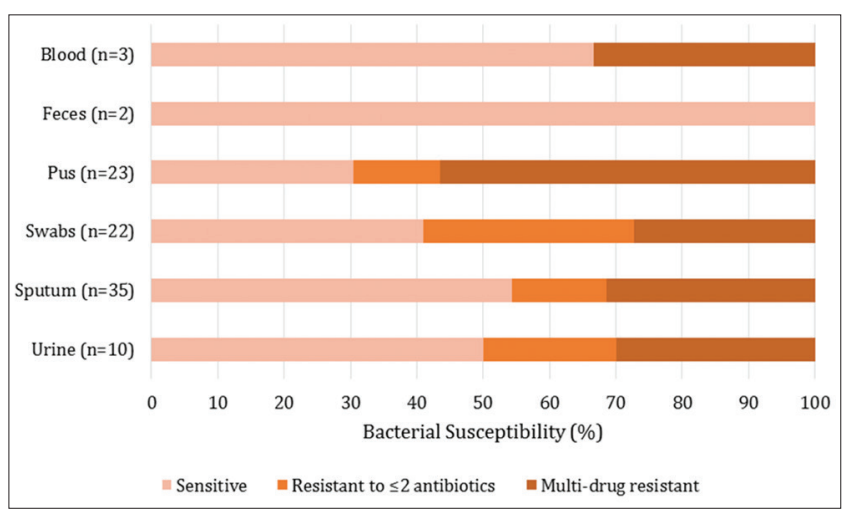

Fig. 2: Bacterial susceptibility of different clinical samples against antibiotics. Total percentage of sensitive, resistant to $\leq 2$ antibiotics, and multidrug resistance is $46.32 \%, 17.89 \%$, and $35.79 \%$, respectively 
The most sensitive test result in the present study was shown to amikacin where $89.47 \%$ of the samples were susceptible to this antibiotic. This result is very comparable with a study conducted on patients in the burns unit at the Menoufia University Hospitals, Egypt, in which $89 \%$ of the isolates were sensitive to amikacin [22]. A recent study from India has also reported a good efficacy of amikacin against $P$. aeruginosa, with $<6 \%$ of unsusceptibility, placing the drug as the most effective one to kill the bacteria among others tested [4]. However, the efficacy of this drug is reportedly lower when tested to samples from nosocomial infections, 80\%, as stated by another study from Egypt [23].

The bacterial isolates are considered to exhibit MDR when the insensitivity is exposed to three or more antibiotics [5]. The percentage of MDR from the present study is somewhat high, almost 36\% among 95 bacterial isolates. However, many previous studies reported a higher percentage of MDR of Pseudomonas. The most recent one, conducted in Rajasthan, India, has reported that the incidence of MDR is $85.45 \%$ [3]. Some other studies worldwide also reveal high level of MDR of $P$. aeruginosa. Prior use of antibiotics, mainly carbapenem and fluoroquinolone, is considered as the major risk factor for the development of MDRPA. Besides, MDR may also occur by both acquisitions of drug resistance: By existing strains and by crossinfection with resistant strains [9].

The present study showed that MDRPA bacteria were mostly derived from pus (13 out of 95 isolates). A recent study conducted in India also reported that $P$. aeruginosa is one of the most common Gram-negative bacteria obtained in the pus. Furthermore, the bacteria are resistant to third-generation cephalosporin such as ceftriaxone, ceftazidime, and cefotaxime [18].

The variation in the percentage of $P$. aeruginosa that is resistant to antibiotics among places and countries may be due to different level of irrational use of antibiotics. Irrational use of antibiotics in the community is a major cause of rising antibiotic resistance. This includes self-medication with antibiotics and poor adherence to dosage regimens [24]. Other factors such as commercial interests and a lack of knowledge about the rational use of antibiotics and antibiotic resistance were also proposed [25]. Early detection will greatly assist in the control of hospital infections caused by these bacteria [21].

\section{CONCLUSION}

The highest percentage of resistance from 95 clinical sample isolates of P. aeruginosa is to ceftriaxone (43.16\%), whereas the least resistance is shown to amikacin (9.47\%). MDRPA is counted $35.79 \%$, mostly found in pus sample.

\section{ACKNOWLEDGMENT}

The authors acknowledge financial support from Directorate General for Higher Education, Ministry of Research, Technology and Higher Education - Republic of Indonesia under the scheme of doctoral dissertation grant 2015. The authors would also like to thank The National Agency of Drug and Food Control, Republic of Indonesia in Padang City for providing the control sample of $P$. aeruginosa ATCC 27853.

\section{REFERENCES}

1. Vahdani M, Azimi L, Asghari B, Bazmi F, Rastegar Lari A. Phenotypic screening of extended-spectrum $\beta$-lactamase and metallo- $\beta$-lactamase in multidrug-resistant Pseudomonas aeruginosa from infected burns. Ann Burns Fire Disasters 2012;25(2):78-81.

2. Strateva T, Yordanov D. Pseudomonas aeruginosa - A phenomenon of bacterial resistance. J Med Microbiol 2009;58(9):1133-48

3. Dawra R, Sharma R, Bachhiwal R, Vyas A. High incidence of multidrug resistant Pseudomonas aeruginosa isolated from infected burn wounds in a tertiary hospital. Int J Curr Microbiol Appl Sci 2017;6(2):1134-9.
4. Rathod VS, Raut SS. Emergence of multi-drug resistant strains among bacterial isolates in burn wound swabs in a tertiary care centre, Nanded, Maharashtra, India. Int J Res Med Sci 2017;5(3):973-7.

5. Falagas ME, Kopterides P. Risk factors for the isolation of multi-drugresistant Acinetobacter baumannii and Pseudomonas aeruginosa: A systematic review of the literature. J Hosp Infect 2006;64(1):7-15.

6. Biswal I, Arora BS, Kasana D, Neetushree. Incidence of multidrug resistant Pseudomonas aeruginosa isolated from burn patients and environment of teaching institution. J Clin Diagn Res 2014;8(5):DC26-9.

7. Metri B, Jyothi P. Antimicrobial resistance of Pseudomonas aeruginosa strains from patients with urinary tract infections in SBMPMC hospital Bijapur, India. Int J Pharm Pharm Sci 2014;6(9):479-81.

8. Soleha M, Elvistra HL, Fitri N, Triyani T. Patterns of Bacterial Resistance to Antimicrobials in Jakarta. Proceeding Center for Biomedical and Pharmaceutical. Jakarta: Health Research Agency; 2009.

9. Falagas ME, Karageorgopoulos DE. Pandrug resistance (PDR), extensive drug resistance (XDR), and multidrug resistance (MDR) among gram-negative bacilli: Need for international harmonization in terminology. Clin Infect Dis 2008;46(7):1121-2.

10. Kalaivani R, Shashikala P, Devi S, Prashanth K, Saranathan R. Phenotypic assays for detection of ESBL and MBL producers among the clinical isolates of multidrug resistant Pseudomonas aeruginosa from a tertiary care hospital. Int J Curr Res Rev 2013;5(17):28-35.

11. Sjahjadi NR, Rasyid R, Rustam E, Restusari L. The prevalence of Multi Drug Resistance (MDR) germs in the Department of Microbiology of M. Djamil Hospital Padang in January 2010 - December 2012). J Kesehatan Andalas 2014;3(3):440-4.

12. Clinical Laboratory Standards Institute. Performance Standards for Antimicrobial Disk Susceptibility Tests: Approved Standard, CLSI Document M02-A11. $11^{\text {th }}$ ed. Wayne, PA: Clinical Laboratory Standards Institute; 2012

13. Gillespie SH. Antibiotic Resistance: Methods and Protocols. New York: Springer Science \& Business Media; 2001.

14. Baker CN, Stocker SA, Culver DH, Thornsberry C. Comparison of the $\mathrm{E}$ Test to agar dilution, broth microdilution, and agar diffusion susceptibility testing techniques by using a special challenge set of bacteria. J Clin Microbiol 1991:29(3):533-8.

15. Bonev B, Hooper J, Parisot J. Principles of assessing bacterial susceptibility to antibiotics using the agar diffusion method. J Antimicrob Chemother 2008;61(6):1295-301.

16. Akingbade OA, Balogun SA, Ojo DA, Afolabi RO, Motayo BO, Okerentugba $\mathrm{PO}$, et al. Plasmid profile analysis of multidrug resistant Pseudomonas aeruginosa isolated from wound infections in South West, Nigeria. World Appl Sci J 2012;20(6):766-75

17. Sadawarte K, Dadarya S, Prabhu T. Antibacterial resistance pattern of Pseudomonas aeruginosa co-isolated with other aerobic bacteria from burn wounds in tertiary care hospital. JEMDS 2014;3(2):464-8.

18. Divyashanthi C, Adithiyakumar S, Bharathi N. Study of prevalence and antimicrobial susceptibility pattern of bacterial isolates in a tertiary care hospital. Int J Pharm Pharm Sci 2015;7(1):185-90.

19. Bassetti D, Cruciani M, Solbiati M, Rubini F, Gandola L, Valenti G, et al. Comparative efficacy of ceftriaxone versus ceftazidime in the treatment of nosocomial lower respiratory tract infections. Chemotherapy 1991;37:371-5.

20. Mody L, Bradley SF, Strausbaugh LJ, Muder RR. Prevalence of ceftriaxone - And ceftazidime-resistant gram-negative bacteria in longterm-care facilities. Infect Control Hosp Epidemiol 2001;22(4):193-4.

21. Jayanthi S, Jeya M. Plasmid profile analysis and bla VIM gene detection of metalo B-lactamase (MBL) producing Pseudomonas aeruginosa isolates from clinical samples. J Clin Diagn Res 2014;8(6):DC16-9.

22. Koura BA, Zaghloul MH, Noha, EM. Plasmid profile of multidrug resistant Pseudomonas aeruginosa strains in a burn unit. Mol Diagn Vaccin 2003;1(1):59-70

23. Mahmoud AB, Zahran WA, Hindawi GR, Labib AZ, Galal R. Prevalence of multidrug-resistant Pseudomonas aeruginosa in patients with nosocomial infections at a university hospital in Egypt, with special reference to typing methods. J Virol Microbiol 2013;23:1-13.

24. World Health Organization. WHO Global Strategy for Containment of Antimicrobial Resistance; 2001. Available from: http://www.who.int/ drugresistance/WHO_Global_Strategy_English.pdf. [Last accessed on 2017 Mar 06].

25. Kotwani A, Wattal C, Joshi PC, Holloway K. Irrational use of antibiotics and role of the pharmacist: An insight from a qualitative study in New Delhi, India. J Clin Pharm Ther 2012;37(3):308-12. 